\title{
How to become a physician in general internal medicine
}

\author{
Jacqui Wise
}

London, UK

Doctors specialising in general internal medicine are part of the acute medical care workforce. Their work involves diagnosing and treating a wide spectrum of diseases and conditions that present acutely to hospital emergency departments and acute medical units. They also refer patients for specialist opinion and care as needed.

Physicians in general internal medicine need to have expertise in diagnostic reasoning and in managing comorbidities, including for elderly patients with frailty and dementia. Most doctors that practise general internal medicine are also trained in another specialty or sub-specialty.

Two phenomena are driving an increasing recognition of the importance of general internal medicine: the rising number of older people with multiple long term conditions and the increasing focus within medicine on specialisation. These factors mean that patients may be referred from one specialist to another without one individual physician taking overall responsibility for their care.

The Royal College of Physicians' Future Hospital Commission report ${ }^{1}$ highlighted the importance of general internal medicine in the delivery of holistic, person centred care. The 2013 Shape of Training review ${ }^{2}$ also emphasised the importance of increasing the number of doctors with generalist skills and recommended that dual training for physicians-general internal medicine alongside a medical specialty-should be standard for trainees in England.

For doctors in training who are considering a career in general internal medicine, there is a choice of two pathways they can take after completing their medical degree and the two year foundation programme. These are the acute care common stem (ACCS) programme and the internal medicine training (IMT) programme. Both are currently three years long and, at the end, doctors must pass the full Membership of the Royal Colleges of Physicians of the United Kingdom (MRCP) diploma before entering the next stage of specialty training.

\section{Internal medicine training programme}

A new IMT programme is currently being introduced. It has been developed in response to recommendations in the Shape of Training report, with the aim of better equipping doctors with the skills needed in the 21 st century NHS.

This three year programme will replace the old two year core medical training programme. More information about the changes can be found on the IMT recruitment website ${ }^{3}$ and the Joint Royal Colleges of Physicians Training Board website. ${ }^{4}$
The programme has mandatory training in geriatric medicine, critical care, and outpatients, but still offers the opportunity to gain a wide range of experience. It also aims to prepare doctors for the management of the acutely unwell patient, with an increased focus on chronic disease management, comorbidity, and complexity.

The programme aims to prepare trainees for the role of medical registrar. At the end of the second year, trainees will have to demonstrate they have the required capabilities to take on the medical registrar role in the third year of the programme.

\section{Acute care common stem programme}

The ACCS curriculum is currently a three year programme during which trainees get experience of acute medicine, critical care, anaesthetics, emergency medicine, and general medical specialties. The programme is currently under review, however, and the new programme will be aligned to the new IMT programme.

It is proposed that the new programme will comprise two years rotating through emergency medicine, acute internal medicine, anaesthetics, and intensive care medicine. This will be followed by completion of years two and three of the IMT programme-making four years in total. It is expected that the new ACCS curriculum will be implemented in 2021 and there will be transitional arrangements for trainees already part way through the programme. More information is available from the IMT programme website. ${ }^{5}$

\section{MRCP}

Trainee doctors will have completed Part 1 of the MRCP examination during the foundation stage of training. They then need to pass their MRCP Part 2 written and Practical Assessment of Clinical Examination Skills examinations in order to be awarded their MRCP (UK) diploma. Workplace based assessments are recorded in an e-portfolio that trainee doctors continue to use in specialty training. More information about the examinations can be found on the MRCP website. ${ }^{6}$

\section{Specialty training}

After completing the MRCP, physicians can progress to specialty training which can take a further three or four years. This can be in general internal medicine alone or in a dual programme. Dual training alongside general internal medicine is possible in a range of specialties including acute internal medicine, respiratory medicine, cardiology, gastroenterology, 
geriatric medicine, renal medicine, and endocrinology and diabetes. Two thirds of medical registrars dual certify in general internal medicine as well as their specialty.

\section{Certificate of completion of training}

After completing three or four years of specialty training, doctors can apply to the General Medical Council for a certificate of completion of training (CCT). ${ }^{7}$ This confirms a doctor has completed an approved training programme and is eligible for the specialist register. Doctors can apply for consultant roles six months before receiving their CCT. Trainees who wish to achieve a CCT in both general internal medicine and another specialty must have completed a training programme that was advertised openly as a dual training programme. They will then receive two CCTs, one in general internal medicine and one in the other medical specialty.

1 Royal College of Physicians. www.rcplondon.ac.uk/projects/outputs/future-hospitalcommission

2 Shape of Training. www.shapeoftraining.co.uk.

3 NHS IMT Recruitment. www.imtrecruitment.org.uk.

Joint Royal Colleges of Physicians Training Board. www.jrcptb.org.uk/imt.

5 NHS IMT Recruitment. About acute care common stem (ACCS). www.imtrecruitment.org. uk/about-imt/about-accs.

6 Membership of the Royal Colleges of Physicians of the United Kingdom/MRCP(UK) examinations. www.mrcpuk.org/mrcpuk-examinations.

7 General Medical Council. www.gmc-uk.org/registration-and-licensing/join-the-register/ registration-applications/specialist-application-guides/guide-to-a-certificate-of-completionof-training

Published by the BMJ Publishing Group Limited. For permission to use (where not already granted under a licence) please go to http://group.bmj.com/group/rights-licensing/ permissions 